\title{
Liquid Rocket Propulsion for Atmospheric Flight in the Proposed ARES Mars Scout Mission
}

\author{
Christopher A.Kuhl ${ }^{\dagger}$, Henry S. Wright ${ }^{\ddagger}$, Craig A. Hunter ${ }^{\S}$ \\ NASA Langley Research Center, Hampton, VA, 23681 \\ Carl S. Guernsey ${ }^{* *}$ \\ Jet Propulsion Laboratory, Pasadena, CA, 91109 \\ and \\ Anthony J. Colozza ${ }^{\dagger+}$ \\ Analex Corporation, NASA Glenn Research Center, Cleveland, OH, 44135
}

\begin{abstract}
Flying above the Mars Southern Highlands, an airplane will traverse over the terrain of Mars while conducting unique science measurements of the atmosphere, surface, and interior. This paper describes an overview of the ARES mission with an emphasis on airplane propulsion needs. The process for selecting a propulsion system for the ARES airplane is also included. Details of the propulsion system, including system schematics, hardware and performance are provided. The airplane has a $6.25 \mathrm{~m}$ wingspan with a total mass of $149 \mathrm{~kg}$ and is propelled by a bi-propellant liquid rocket system capable of carrying roughly $48 \mathrm{~kg}$ of MMH/MON3 propellant.
\end{abstract}

\section{Introduction}

$\mathrm{T}$ The advances in aerial flight and modern rocketry during the first half of the twentieth century expanded our capabilities for exploration by pioneering the realm of high speed and high altitude flight. Now, nearly a half century later, NASA is continuing this pioneering spirit by using this combination of technologies in a new and unique way to expand our abilities for solar system exploration.

The proposed Mars Scout mission ARES (Aerial Regional-scale Environmental Survey), using an airplane with a liquid propellant rocket engine, is envisioned to be the first powered flight through the atmosphere of another planet. ARES will provide NASA with the ability to explore inaccessible regions of Mars, returning previously unobtainable science data. The ARES mission was one of four Mars Scout proposals selected in December 2002 for continued study and refinement. A detailed ARES Concept Study Report was submitted to the Mars Scout program in May 2003. This paper describes the liquid rocket propulsion system concept for the ARES airplane.

\section{Mission Overview}

Because Mars Scout missions are principal investigator-led, science-focused endeavors, the ARES mission profile was developed with science goals driving all mission parameter considerations. Extensive design trade studies and design cycles enabled the development of a low-risk implementation concept which achieved all of the science goals and objectives ${ }^{1}$. Trade studies ranging from platform selection, interplanetary mission design, and aerodynamic configurations have been performed over the past few years as part of the development process ${ }^{2}$. The resulting Mars airplane concept achieves the high-value science objectives of the ARES mission with a simple, lowrisk design. Driving requirements for the overall ARES mission are derived from desired science measurements and

\footnotetext{
${ }^{\dagger}$ Aerospace Engineer, Exploration Engineering Branch

‡ Aerospace Engineer, Exploration Engineering Branch

$\S$ Aerospace Engineer, Configuration Aerodynamics Branch

${ }^{* *}$ Principal Engineer, Thermal and Propulsion Systems Section, Sr. Member AIAA

${ }^{\dagger \dagger}$ Aerospace Systems Engineer, Power and Propulsion Technology, AIAA Member
} 
program limitations set for Mars Scout missions ${ }^{1}$. Key ARES science measurements driving the propulsion design include atmospheric measurements between 1 to $2 \mathrm{~km}$ altitude, an aeromagnetic survey of the Mars surface requiring a flight traverse of at least $500 \mathrm{~km}$, and a flight time greater than 1 hour. Figure 1 illustrates the flight path which blends all of these requirements.

The ARES Atmospheric Flight System (AFS) is composed of the airplane, its subsystems and the science payload. Continued analyses and focused trade studies, augmented by experimental results from wind-tunnel and flight testing, have matured the airplane and subsystem designs well beyond the fundamental conceptual level. A robust airplane configuration has been achieved through three major design cycles resulting in significant vehicle performance and reliability improvements. The airplane geometry is depicted in Figure 2. Delivery of the ARES airplane into the atmosphere of Mars requires an entry aero-shell. Packaging of the airplane into the entry aero-shell, as shown in Figure 3, in a way that accommodates the environments of launch and entry provides the primary configuration constraints for the ARES airplane. The airplane shape is derived from the aero-shell packaging constraints and the need for subsonic flight required by the science measurements. Table 1 provides the overall mass and geometric properties for the ARES Atmospheric Flight System³ ${ }^{3}$.

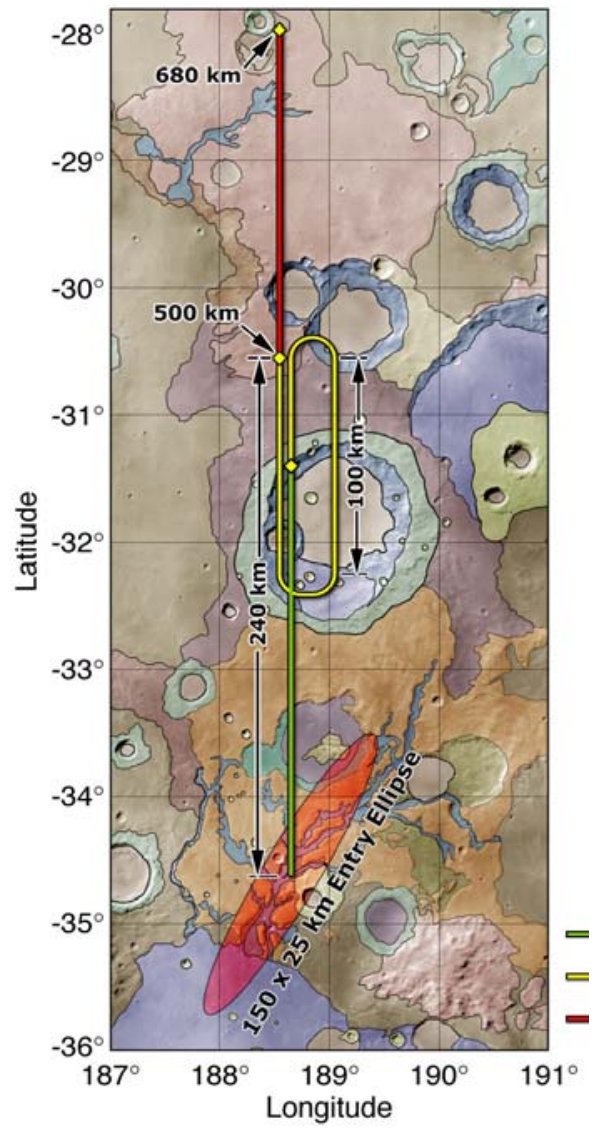

Figure 1. ARES Planned Flight Traverse

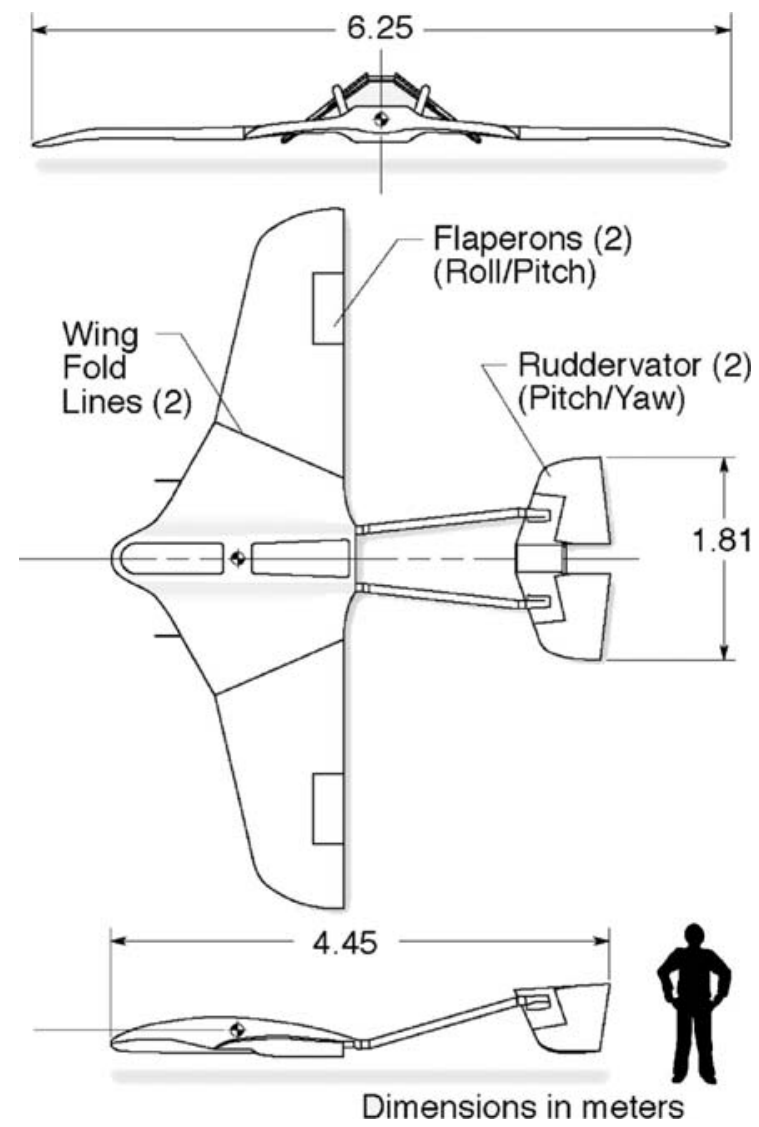

Figure 2. ARES Airplane Geometry

Table 1. ARES Airplane Parameters

\begin{tabular}{|l|l|}
\hline Parameter & Value \\
\hline Wing Span & $6.25 \mathrm{~m}$ \\
\hline Overall Length & $4.45 \mathrm{~m}$ \\
\hline Overall Height & $0.7 \mathrm{~m}$ \\
\hline Reference Wing Area & $7.0 \mathrm{~m}^{2}$ \\
\hline Mean Aerodynamic Chord & $1.25 \mathrm{~m}$ \\
\hline Total Mass & $149 \mathrm{~kg}$ \\
\hline
\end{tabular}




\section{Propulsion System Trade Studies}

Propulsion system characteristics and capabilities are critical to establishing an aircraft's performance and flight envelope. This is especially true for planetary aircraft that must be stowed in an aero-shell (See Figure 3), which imposes strict mass and volume limits on the aircraft and subsystems. In selecting a propulsion system for the ARES airplane, two competing criteria were used to evaluate each system. The science return from the mission depends heavily on the flight range of the aircraft. Therefore, the first criterion is for the propulsion system to achieve the baseline science target requirement of at least $500 \mathrm{~km}_{\text {of flight }}{ }^{1}$. The second criterion relates to implementation risk of the propulsion system. The cost constraints and risk posture desired for Scout missions require maximizing the use of existing, flight proven hardware. Extraction and deployment of the airplane from the aero-shell increases mission risk and any additional deployments necessitated by a propulsion subsystem, such as propeller blades, are considerations in the final propulsion system selection. Various propulsion system options, listed in Table 2, were examined to determine the candidate that balanced the competing criteria of maximizing flight range and minimizing technical risk ${ }^{4}$. To stay within mass constraint of the aircraft, the propulsion system mass was also constrained. For a 149 $\mathrm{kg}$ aircraft, the maximum propulsion system mass is approximately $63 \mathrm{~kg}$ including propellants ${ }^{3}$. Results of the propulsion system analyses are listed in Table 2 and described below.

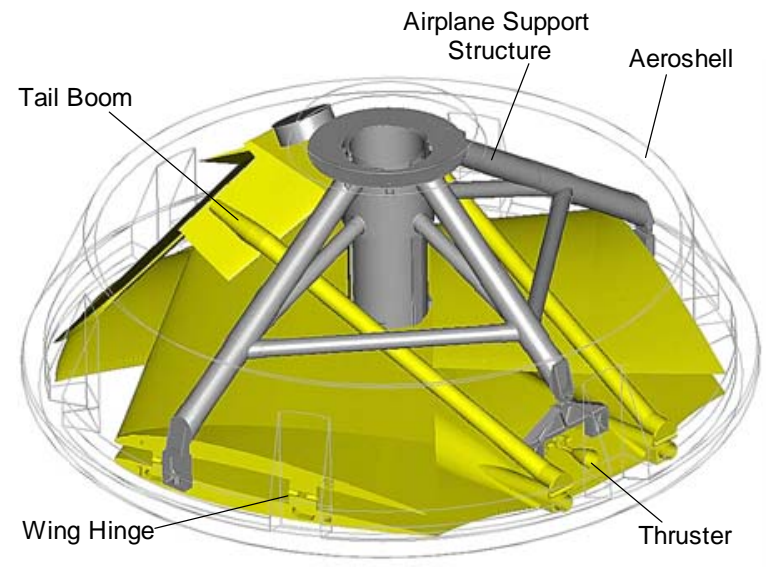

Figure 3. ARES Airplane Aero-shell Configuration

Table 2. Comparison of Propulsion System Options

\begin{tabular}{|c|c|c|c|c|c|c|c|}
\hline $\begin{array}{c}\text { Propulsion } \\
\text { Category }\end{array}$ & System & $\begin{array}{c}\text { Dry Mass } \\
{[\mathbf{k g}]}\end{array}$ & $\begin{array}{c}\text { Fuel Load } \\
{[\mathbf{k g}]}\end{array}$ & $\begin{array}{c}\text { Flight } \\
\text { Hours }\end{array}$ & $\begin{array}{c}\text { Range } \\
{[\mathbf{k m}]}\end{array}$ & TRL & $\begin{array}{c}\text { Development } \\
\text { Effort }\end{array}$ \\
\hline $\begin{array}{c}\text { Electrical } \\
\text { Propulsion Systems }\end{array}$ & Fuel Cell & 48 & 15 & 3.0 & 1512 & $4-5$ & HIGH \\
\cline { 2 - 8 } $\begin{array}{c}\text { Combustion Engine } \\
\text { Systems }\end{array}$ & Battery & 63 & 0 & 0.4 & 202 & $4-6$ & MED \\
\cline { 2 - 8 } & Piston Expander Engine & 19 & 44 & 2.0 & 1008 & $4-5$ & HIGH \\
\hline \multirow{2}{*}{ Rocket Systems } & Bipropellant Rocket & 15 & 48 & 1.2 & 605 & $7-9$ & LOW \\
\cline { 2 - 8 } & Monopropellant Rocket & 11 & 52 & 0.9 & 454 & $7-9$ & LOW \\
\hline
\end{tabular}

\section{A. Electrical Propulsion Systems}

A simplified fuel cell system can be used to generate electrical power, which in turn can be used to power an electric motor and spin a propeller to generate thrust. This system can achieve flight of $1512 \mathrm{~km}$, carrying $15 \mathrm{~kg}$ of fuel with a $48 \mathrm{~kg}$ dry mass. The relative newness of the technology (TRL 4) and lack of experience in utilizing a fuel cell as the main power system in an aircraft makes it a very high risk item.

A battery propulsion system is the simplest of all systems considered and requires fewer active controls and has no mechanical components, aside from the drive train. However, batteries with high specific power have low discharge rates. This low rate forces the battery capacity higher and adds significant mass to the system. The battery systems analyzed failed to satisfy the baseline science requirement, achieving a range of only $202 \mathrm{~km}$.

\section{B. Combustion Engine Systems}

The concept of using a piston expander engine as a primary propeller driver dates back to the first studies of Mars aircraft design in the late 1970's, ${ }^{5,6}$ The design is based on the Mini-Sniffer, high altitude, unmanned vehicle program. The piston expander engine analysis shows a capability of $1008 \mathrm{~km}$ of flight carrying $44 \mathrm{~kg}$ of hydrazine and $19 \mathrm{~kg}$ of propulsion hardware. Piston expander technology maintains a TRL of $\sim 4-5$ and a significant development program would need to be implemented to produce an engine that can operate within the Mars environment. 
The 4-cycle internal combustion (IC) engine option for Mars flight is similar to a conventional aircraft engine but would require design changes to operate within the thin atmosphere of Mars using a bi-propellant fuel and oxidizer. This option resulted in the longest flight range of $2066 \mathrm{~km}$, with a dry-mass of $21 \mathrm{~kg}$ and a hydrazine fuel load of $42 \mathrm{~kg}$. The combustion engine technology maintains a low TRL for a planetary flight application and would require a significant amount of design, testing and qualification for use in a Mars airplane.

\section{Rocket Systems}

Rocket propulsion systems have a long heritage in space flight applications as well as in rocket-powered aircraft. There are a number of propellants that can power a rocket propelled aircraft within the Mars environment. Several propellant combinations were considered, based on specific impulse, a stable liquid state during interplanetary cruise, and spaceflight heritage ${ }^{4}$. Potential propellant combinations were narrowed down to one monopropellant and two bi-propellant options, listed in Table 3. Hydrazine has been used in spacecraft for several decades, typically in low thrust applications like satellite station keeping. Hydrazine is decomposed through a catalytic reaction with a metal oxide. The bi-propellant combination monomethyl hydrazine (MMH) and nitrogen tetroxide (MON3) is commonly used in the satellite industry for reaction control thrusters. Both hydrazine and MON3 have freezing

Table 3. Rocket System Propellant Candidates

\begin{tabular}{|c|c|c|c|c|c|c|}
\hline & Propellant & Type & $\begin{array}{c}\text { Freezing } \\
\text { Point }\left({ }^{\circ} \mathbf{C}\right)\end{array}$ & $\begin{array}{c}\text { Density @ } \\
\mathbf{2 0} \mathbf{C}^{\circ} \mathbf{C} \\
\left(\mathbf{g m m}^{\mathbf{c}} \mathbf{c m}^{3}\right)\end{array}$ & $\begin{array}{c}\text { Comb. } \\
\text { Temp. } \\
\left({ }^{\circ} \mathbf{C}\right)\end{array}$ & Isp (sec) \\
\hline $\begin{array}{c}\text { Mono- } \\
\text { propellant }\end{array}$ & Hydrazine $\left(\mathrm{N}_{2} \mathrm{H}_{4}\right)$ & Fuel & $1.5^{\circ} \mathrm{C}$ & 1.008 & 633 & $199-230$ \\
\hline $\begin{array}{c}\mathrm{Bi}- \\
\text { Propellant }\end{array}$ & $\begin{array}{c}\text { Monomethyl Hydrazine }(\mathrm{MMH})\left(\mathrm{N}_{2} \mathrm{H}_{6} \mathrm{C}\right) \\
\text { Nitrogen Tetroxide (MON3) } \\
\left(97 \% \mathrm{~N}_{2} \mathrm{O}_{4}, 3 \% \mathrm{NO} \text { by weight) }\right.\end{array}$ & $\begin{array}{c}\text { Fuel } \\
\text { Oxidizer }\end{array}$ & $\begin{array}{c}-52.5^{\circ} \mathrm{C} \\
-11.2^{\circ} \mathrm{C}\end{array}$ & $\begin{array}{c}0.874 \\
1.39\end{array}$ & 3122 & $285-310$ \\
\hline
\end{tabular}

points above expected temperatures during interplanetary cruise, and would therefore require proper thermal control. The combination of MMH and MON3 has a much higher specific impulse than hydrazine but bi-propellant systems are typically more complicated than monopropellant systems.

To evaluate the rocket propulsion system options, a number of designs were considered. These ranged from passive blow-down systems to regulated systems that were controlled either by on / off pulsing or by controlling the propellant flow to the thruster. For each type of control scheme, both monopropellant and bipropellant systems were considered. The analysis of rocket systems resulted in a flight range of $605 \mathrm{~km}$ for the bi-propellant system and 454 $\mathrm{km}$ for the monopropellant system. Rocket propulsion systems, due to extensive use in military applications and the satellite industry, have a high technology readiness level between 7 and 9, which is the desirable technology maturation level for a Mars Scout mission ${ }^{4}$.

\section{Airplane Propulsion System Selection}

The final selection of a propulsion system for the ARES airplane depended on options requiring minimal developmental effort and low technical risk while meeting science range requirements. For the electrical systems and combustion engines, a propeller is required to generate thrust, and there are significant challenges to operating a propeller in the Mars atmosphere. The propeller would need to operate near the sonic limit at its tip, which would place the blade operation in a low Reynolds number, high subsonic Mach number environment. This is outside the regime of conventional propeller design. Additionally, the size of the propeller would require it to be folded to fit within the aero-shell then deployed with the airplane during entry. Due to the aerodynamics and required deployment, the propeller represents a considerable risk item for airplane operation ${ }^{4}$. The technical risk caused by the need for a propeller eliminated the electrical and combustion engine systems, so the rocket system was selected for the baseline ARES airplane propulsion system.

Two rocket systems were viable options for a Mars airplane application, a MMH/MON3 bi-propellant system and a hydrazine mono-propellant system. Brief consideration was given to use of a MMH/MON25 bipropellant combination because of its lower freezing temperature, but introducing this relatively immature technology was inconsistent with the risk posture of the Scout program. The final selection was driven by a system analysis that examined the difference in available fuel load to support the flight range of the two systems. Since the 
monopropellant system is less complex, a potentially lower dry-mass would permit additional fuel load. However packaging constraints of the airplane require that even the monopropellant system have dual fuel tanks, similar to the bi-propellant system, thus essentially the same hardware configuration. Dry-mass difference between the two systems is effectively negligible, and overall performance is based solely on the specific impulse of the propellants listed in Table 3. The monopropellant system can not carry enough fuel to achieve the baseline science requirement of $500 \mathrm{~km}$ or greater flight range. Therefore, a bi-propellant rocket system was selected for the ARES airplane.

\section{Propulsion System Design}

The ARES airplane baseline propulsion system is a regulated bi-propellant system with pulsed thruster control. Major components of this system consist of fuel and oxidizer tanks, helium pressure tank, and a thruster. The schematic layout of the ARES propulsion subsystem is shown in Figure 4 and the layout of hardware in the airplane is shown in Figure 5.

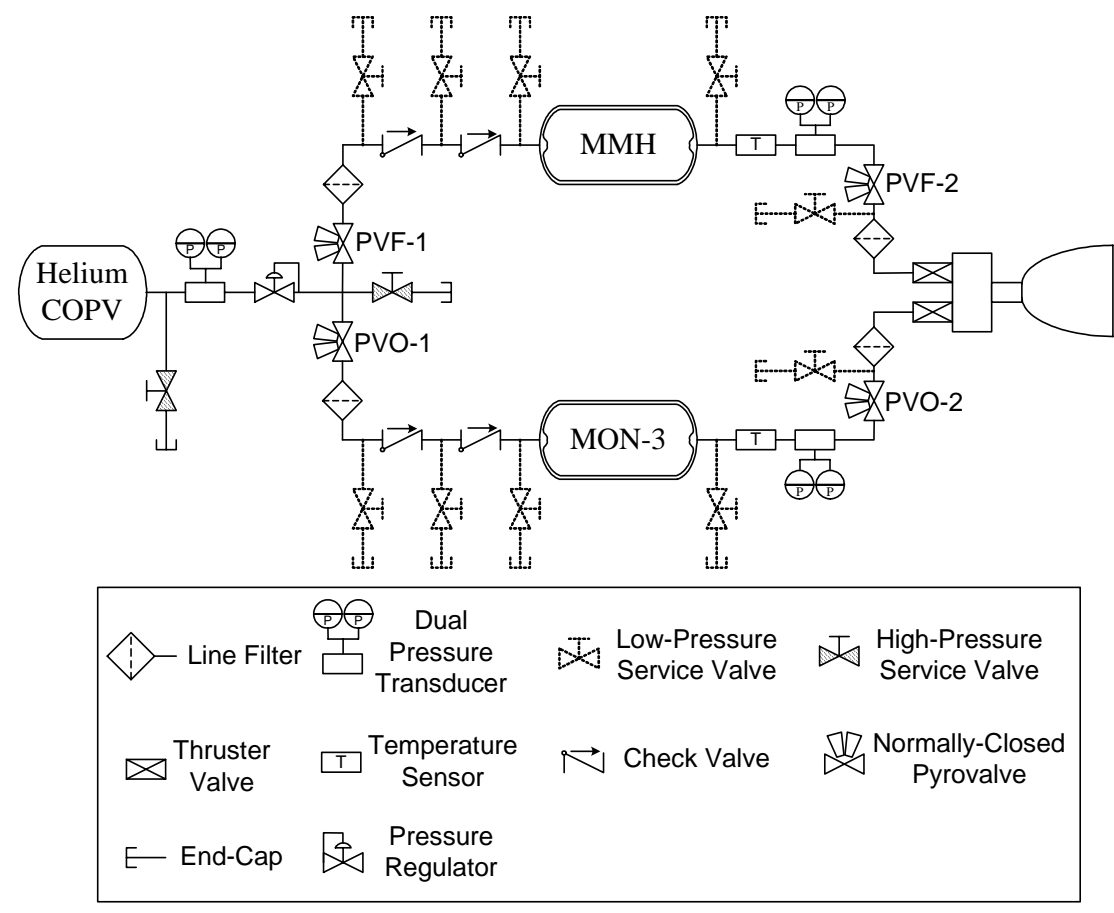

Figure 4. Bi-Propellant Propulsion System Schematic

\section{A. Titanium Propellant Tanks}

The ARES fuel and oxidizer tanks will be identical, cylindrical pressure vessels made of titanium, with a maximum expected operating pressure (MEOP) of 20 bar and minimum yield and burst factors-of-safety of 1.25 and 1.4, respectively. A volume of approximately 24 liters per tank would allow a propellant load of $18 \mathrm{~kg}$ of MMH or $30 \mathrm{~kg}$ of MON3 to be accommodated with $10 \%$ ullage and $0.5 \%$ residual volumes. These tanks will include screenand-channel type propellant management devices (PMDs) to ensure that propellant can be acquired under Mars $g$ axial acceleration and any loads that may be encountered during the propulsion system operation. Baffles may be included to minimize propellant slosh interaction with the aircraft control system. While use of composite overwrapped propellant tanks could offer mass savings, it was felt that such a development would be inconsistent with the risk posture desired for a Scout proposal.

\section{B. Composite Helium Tank}

The helium pressure tank is a conventional, composite-over wrapped pressure vessel with a MEOP of 210 bar and minimum burst factor of safety of 1.5. To minimize non-recurring engineering costs, the tank will be based on the design of an existing tank with a higher pressure rating. The design would be modified to reduce the amount of graphite over-wrap applied to the tank liner. Like the propellant tank, any extra efforts to reduce mass by modifying the liner thickness were deemed inappropriate for a Scout proposal. 


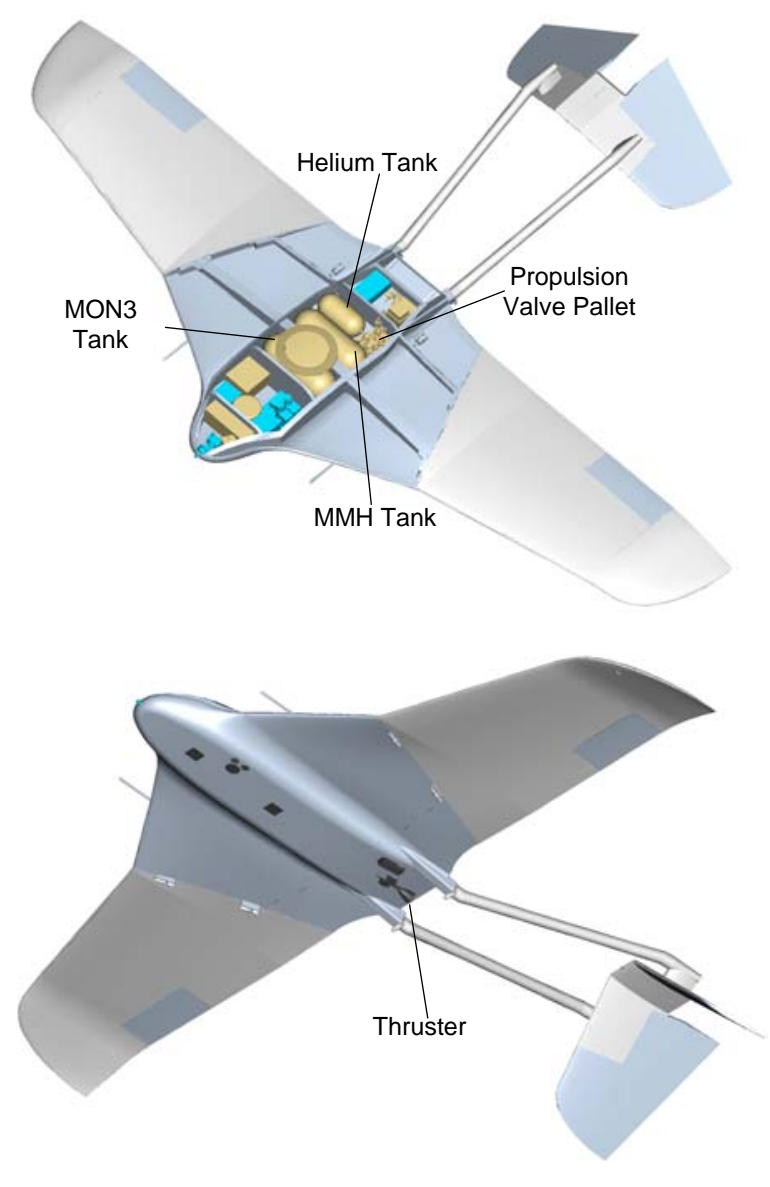

Figure 5. Propulsion Hardware Configuration

\section{Rocket Thruster}

The baseline thruster for the ARES airplane is the Aerojet AJ10-220 reaction-control thruster, which was developed and qualified for a U. S. Air Force satellite. This provides a thrust of $62 \mathrm{~N}$ and a cruise thrust margin of $35 \%$ - 50\% when operated in pulsed-mode with a duty cycle between $0.1 \mathrm{~Hz}$ and $0.5 \mathrm{~Hz}$. The existing thruster design uses fairly massive mounting hardware to reduce environmental loads on the thruster and provide a heat sink for the thruster's head end. Testing of this thruster under the expected ARES mission environments and duty cycles will be conducted under an ARES phase-B effort.

In order to evaluate the potential impact of the rocket plume on the aircraft's tail structure, an isolated plume CFD simulation was conducted. Color contours of Mach number are shown in Figure 6, along with a line contour indicating the thermal edge of the plume at $\mathrm{T}_{\mathrm{o}}=220 \mathrm{~K}$. The nozzle stagnation temperature is $3395 \mathrm{~K}$ and the free-stream stagnation temperature is $199 \mathrm{~K}$. This analysis shows that there is sufficient clearance between the $220 \mathrm{~K}$ edge of the plume and the tail surfaces and support booms to preclude any thermal impingement effects. In addition, the limited influence of the plume on the surrounding free-stream indicates that flow around the tail surfaces will not be changed dramatically by the presence of the plume.

\section{Hardware for Propellant Isolation}

Since the propellants are hypergolic, it is critical to ensure isolation of the fuel and oxidizer to avoid inadvertent ignition in any part of the feed system. Normally-closed, pyrotechnically-actuated valves ("pyro valves") PVF-1 and PVO-1 are used to isolate
ks and to prevent propellant vapor migration prior to the high pressure helium supply from both propellant tanks and to prevent propellant vapor migration prior to
system operation. Redundant check valves are used to ensure that there is no vapor or liquid transfer and mixing of the hypergolic propellants during the operation of the system. The possibility exists, during the long periods of inactivity, for fuel or oxidizer to seep through the check valves and condense in upstream sections of the feed system $^{7}$. To minimize trapping any condensed propellant in dead-end upstream sections, the series-redundant check valves for the fuel and oxidizer are located downstream of the pyro valves, which provide the long duration isolation function. Downstream of the propellant tanks, normally closed pyro valves PVF-2 and PVO-2 are also used to provide a redundant seal against external leakage of the propellant through the single-seat thruster valves. In addition to increasing reliability, such redundant seals are required for safety during ground handling. All manual service valves also incorporate redundant seals. The other propulsion system components consist of off-the-shelf hardware with no particularly unique characteristic for the ARES mission.

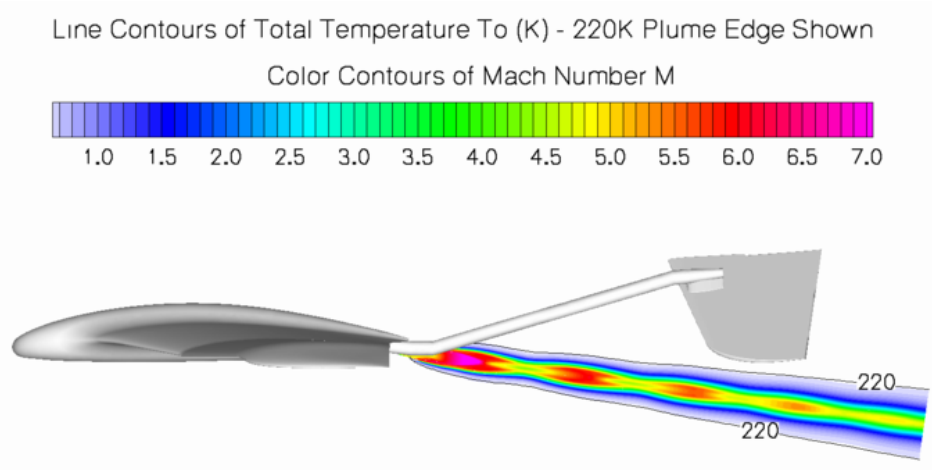

Figure 6. Rocket Plume CFD Analysis 


\section{Propulsion System Operation and Performance}

During propulsion servicing, service valves shown in Figure 4 will be used to ensure that there is no pressure gradient across the check valves when the propellant tanks are pressurized. Redundant pressure transducers are shown on both the oxidizer and fuel tanks to allow the pre-launch pressures to be monitored by ground support equipment during periods when the spacecraft is powered off.

Following launch, the thruster valves will be opened briefly to ensure that the lines downstream of PVF-2 and PVO-2 are evacuated. Approaching Mars and shortly before atmospheric entry, those pyro valves will be commanded open by the on-board command sequence to allow filling of the propellant lines. Once the lines are primed, the pyro valves PVF-1 and PVO-1 are commanded open to pressurize the propellant tanks and fully prepare the system for engine operation. After the airplane has been extracted from the aero-shell, deployed and has acquired stable flight, the thruster will begin a pulse-mode firing in response to the GN\&C flight software. The airplane will fly under the thrust of this system until one or both propellants are exhausted.

The performance summary of the ARES airplane bi-propellant rocket system is given in Table 4 and a flight profile is shown in Figure 7.

Table 4. Propulsion System Performance Summary

\begin{tabular}{|l|l|}
\hline Parameter & Value \\
\hline Propellant Load & $48 \mathrm{~kg}$ \\
\hline Fuel & $18 \mathrm{~kg}-$ MMH \\
\hline Oxidizer & $30 \mathrm{~kg}-$ MON3 \\
\hline Thrust & $62 \mathrm{~N}$ \\
\hline Isp & $\sim 285 \mathrm{~s}$ \\
\hline Flight Duration & $72 \mathrm{~min}$ \\
\hline Range & $605 \mathrm{~km}$ \\
\hline
\end{tabular}

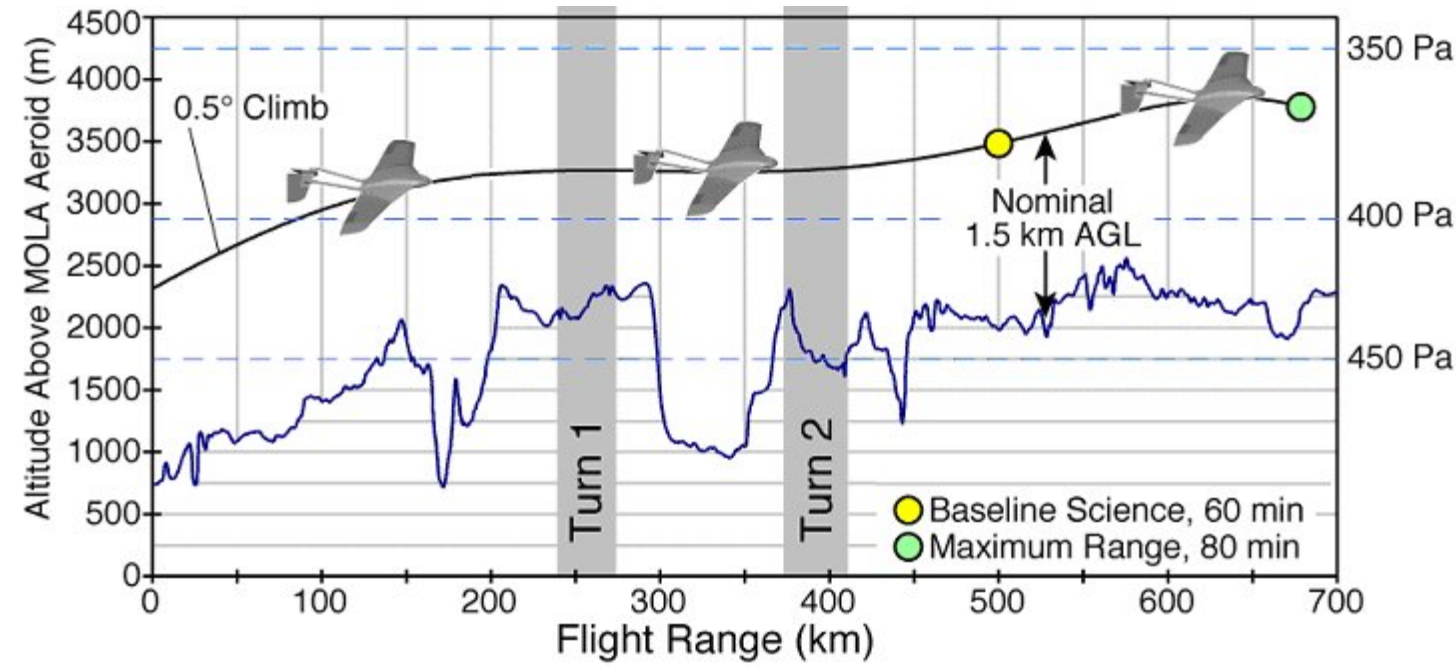

Figure 7. ARES Flight Profile and Performance Summary 


\section{Future Work on the ARES Airplane}

There are on-going efforts to continue maturing technologies that are critical to the ARES mission. Near term efforts will involve a detailed propulsion system design study, expanding on the work described in this paper, that will address propellant combinations, system configuration, and component selections in greater detail. An assessment of potential thruster designs, tank and PMD configurations will also be conducted, and a flight qualification strategy for the design, fabrication, testing and flight certification of a Mars airplane propulsion system to meet a 2011 launch opportunity will be developed.

Long-term needs of a Mars aerial platform will require longer flight durations. The flight duration achievable from a chemical rocket system can be increased by reducing system dry-mass, but flight is essentially limited to about 90 minutes, beyond which the fuel load becomes prohibitively large. To achieve flight durations of 2 or more hours, more efficient propulsion system technologies need to be developed. A likely follow-on to the current baseline rocket system is the hydrazine piston-expander combustion engine. Mars airplane concepts studied over the last twenty-five years considered the hydrazine engine in the trade-space of potential propulsion systems. The original Mars Airplane study from the late 1970s was the first to use a scaled version of the original "Akkerman engine" ${ }^{\text {, }}$ followed later in the 1990s with the Ames Canyon Flyer ${ }^{8}$ and the Mars Micro-mission. To capitalize on more efficient propulsion systems such as the hydrazine engine, or any other combustion engine or electrical system, a propeller capable of operating in the Mars atmosphere and designed to be effectively packaged and deployed is a critical item for future Mars airplanes.

\section{Conclusion}

The ARES Atmospheric Flight System involves a unique application of a liquid rocket propulsion system. This system enables the achievement of all of ARES science objectives and fits within mission constraints. Although ARES was not selected for the 2007 Mars launch opportunity, the potential for fundamental new understanding of the nature of Mars' atmosphere, surface, and interior that only an aerial platform can achieve, and which ARES is uniquely designed to accomplish, will compel an eventual aerial flight on this planet.

\section{References}

${ }^{1}$ Levine, Joel S. et. Al.: "Science from a Mars Airplane: The Aerial Regional-scale Environmental Survey (ARES) of Mars," AIAA 2003-6576.

${ }^{2}$ Guynn, M. D.; Croom, M. A.; Smith, S. C.; Parks, R. W.; Gelhausen, P. A.: "Evolution of a Mars Airplane Concept for the ARES Mars Scout Mission,” AIAA 2003-6578.

${ }^{3}$ Wright, H.S., Croom, M.A., Braun, R.D., Qualls, G. D., Levine, J.S., “ARES Mission Overview - Capabilities and Requirements of the Robotic Aerial Platform,” 2nd AIAA Unmanned Systems, Technologies, and Operations “Air, Space, Land, and Sea” Conference, September 2003.

${ }^{4}$ Colozza, A.J., “Comparison of Mars Aircraft Propulsion Systems,” NASA CR-2003-212350, May 2003.

${ }^{5}$ Reed, R.D. (1978), “High-Flying Mini-Sniffer RPV: Mars Bound,” Astronautics and Aeronautics, Vol. 16, No. 6, pp 26-39

${ }^{6}$ Clarke, V.C., Kerem, A., “A Mars Airplane...Oh Really?,” AIAA-79-0067, 17th Aerospace Sciences Meeting, 15-17 January, 1979.

${ }^{7}$ Guernsey, Carl S., "Propulsion Systems Lessons Larned From The Loss of Mars Observer,” AIAA-2001-3630.

${ }^{8}$ Smith, S.C., Hahn, A.S., et al, “The Design of the Canyon Flyer, An Airplane for Mars Exploration,” AIAA00-16394, 38th Aerospace Sciences Meeting \& Exhibit, 10-13 January 2000. 